\title{
CHẤT LƯợNG CUỘC SỐNG CỦA NGƯờI CAO TUỔI TẠI XÃ THẠCH THÁN, HUYỆN QUỐC OAI, THÀNH PHỐ HÀ NộI NĂM 2021
}

\author{
Vũ Minh Tuấn1, Phùng Chí Ninh², Nguyễn Hồng Uyên²,
} Lê Huyền Trang ${ }^{3}$, Phạm Thị Thu Huyền'1

\section{TÓM TẮT}

Môt nghiên cứu mô tả cắt ngang trên 200 người $\geq$ 60 tuổi tai xã Thach Thán, huyện Quốc Oai, thành phố Hà Nội năm 2021 để khảo sát về tình trạng chất lượng cuộc sống với mục tiêu mô tả thực trạng chất lượng cuộc sống của người cao tuổi bằng bộ công cụ EQ-5D5L. Kết quả cho thấy tỷ lệ người cao tuổi xếp loại chất lượng cuộc sống tốt chiếm $51,5 \%$. Chỉ số EQ-5D trung bình của người cao tuổi là $0,77(S D= \pm 0,13)$. Có mối liên quan giữa chất lượng cuộc sống của người cao tuổi và nhóm tuổi, tình trạng hôn nhân, giới tính, trình đô học vấn, hoàn cảnh sống, giúp đỡ, nghề nghiệp, điều kiện kinh tế, số lần bị ốm tháng trước khi nghiên cứu, sổ bênh mạn tính bị mắc, khám sức khỏe định kỳ, tự đánh giá sức khỏe.

Tư khóa: chất lượng cuộc sống người cao tuổi, EQ-5D, EQ-5D Việt Nam.

\section{SUMMARY}

\section{QUALITY OF LIFE OF THE ELDERLY IN \\ THACH THAN COMMUNE, QUOC OAI DISTRICT, HANOI CITY IN 2021}

A cross-sectional descriptive study on 200 people $\geq 60$ years old in Thach Than commune, Quoc Oai district, Hanoi city in 2021 to survey the status of quality of life with the aim of describing the status of quality of life of elderly people with the EQ-5D-5L toolkit. The results show that the proportion of elderly people who rank good quality of life accounts for $51.5 \%$. The average EQ-5D index of the elderly is 0.77 $(S D= \pm 0.13)$. There is a relationship between the quality of life of the elderly and age group, marital status, gender, education level, living situation, help, occupation, economic conditions, number of times of illness in the previous month before research, number of chronic diseases, periodical health examination, health self-assessment

Keywords: quality of life for the elderly, EQ-5D, EQ-5D Vietnam.

\section{I. ĐĂT VẤN ĐỀ}

Già hóa dân số đang nổi lên như một thách thức đối với vấn đề chính sách chăm sóc sức khỏe trên toàn thế giới, vì thế chất lượng cuộc sống (CLCS) của người cao tuổi (NCT) là vấn đề

\footnotetext{
${ }^{1}$ Viện Đào tạo YHDP\&YTCC, Trường Đại học Y Hà Nội, ${ }^{2}$ Trường Đại họ Y Hà Nội,

${ }^{3}$ Bênhh viện Nhi trung ương

Chịu trách nhiệm chính: Vũ Minh Tuấn

Email: vuminhtuan@hmu.edu.vn

Ngày nhận bài: 16.8.2021

Ngày phản biên khoa hoc: 11.10.2021

Ngày duyệt bài: 19.10.2021
}

rất được quan tâm. Việt Nam cũng đã trải qua một quá trình chuyển đổi sâu sắc kéo dài vài thập kỷ. Là một nước có thu nhập trung bình thấp, nhưng Việt Nam đã sớm bước vào giai đoạn già hóa dân số năm 2011 và nằm trong số 10 nước có tốc độ già hóa nhanh nhất thế giới. Dân số già đưa ra môtt thách thức nghiêm trong về chính sách đối với Chính phủ Việt Nam, vì nó đòi hỏi những khoản chi lớn cho chăm sóc sức khỏe và các hỗ trợ xã hôii khác [1].

Tổng cục Dân số - KHHGĐ nhân định rằng CLCS của NCT còn hạn chế, trong khi NCT là một trong những nhóm người yếu thế và dễ bi tổn thương nhất trong xã hội. Người cao tuổi vừa là chủ thể của sự già hóa, vừa là đối tượng chị tác động của già hóa trên các phương diện về kinh tể và việc làm, tinh thần và xã hội, sức khỏe và chất lượng cuộc sống. Cùng với quá trình lão hóa, NCT dễ mắc bênh và thường rất phức tap với nhiều bệnh tật kèm theo, chủ yếu là các bệnh mạn tính và có xu hướng trở thành nguyên nhân gây tàn tật [2].

Sức khỏe ảnh hưởng trực tiếp đến tất cả các khía cạnh trong đời sống hàng ngày của NCT, đặc biệt là chất lượng cuộc sống. Mục đích của nghiên cứu này nhằm đánh giá thực trạng chất lượng cuộc sống của người cao tuổi tại xã Thach Thán, huyện Quốc Oai, Thành phố Hà Nội năm 2021 và một số yếu tố liên quan đến chất lượng cuộc sống.

\section{II. ĐỐI TƯợNG VÀ PHƯƠNG PHÁP NGHIÊN CỨU}

2.1. Đối tượng, địa điểm và thời gian nghiên cứu. Nghiên cứu được thực hiện trên người cao tuổi (từ 60 tuổi trở lên) tại xã Thạch Thán, Huyện Quốc Oai, Hà Nội từ tháng 02-04 năm 2021.

Tiêu chuẩn lựa chọn: Người cao tuổi sống từ 6 tháng trở lên tại địa bàn nhiên cứu, có khả năng giao.

Tiêu chuẩn loại trừ: NCT tuổi mắc các bệnh về tâm thần, về sa sút trí tuệ (theo chẩn đoán y khoa hiện tại, theo tiền sử bệnh qua sổ khám chữa bệnh của NCT) hoặc những người không còn khả năng giao tiếp.
2.2. Phương pháp nghiên cứu
Thiết kế nghiên cứu: Mô tả cắt ngang
Cỡ mẫu và cách chọn mẫu: 
+ Cõ mẫu: ước lượng một tỉ lệ:

$\mathbf{n}=Z_{1-\alpha / 2}^{2} \frac{p(1-p)}{(p \varepsilon)^{2}}$

Với $p=0,9$ (tỷ lệ NCT ở vùng nông thôn có điểm CLCS xếp hạng ở mức dưới trung bình theo nghiên cứu của Hoàng Văn Minh [3]), tính ra cõ mẫu 200 người cao tuổi.

+ Cách chọn mẫu: Chúng tôi tiến hành lấy mẫu nhiều giai đoạn ở 5 thôn tại xã Thạch Thán, huyện Quốc Oai, thành phố Hà Nội.

Giai đoạn 1: Chọn ngẫu nhiên 5 thôn trong 10 thôn để đưa vào nghiên cứu.

Giai đoạn 2: Lập danh sách người cao tuổi của 5 thôn được chọn.

Giai đoạn 3: Chọn ngẫu nhiên người cao tuổi đầu tiên sau đó sử dụng phương pháp cổng liền cổng để tiến hành thu thập người cao tuổi tiếp theo.

Người cao tuổi đáp ứng tiêu chuẩn lựa chọn và tiêu chuẩn loại trừ được đưa vào nghiên cứu sau khi thông báo về mục đích nghiên cứu và được sự đồng ý của đối tượng. Phỏng vấn trực tiếp người cao tuổi về nhân khẩu học, chất lượng cuộc sống theo mẫu có sẵn là bộ câu hỏi EQ-5D-5L.

Cách tính điểm và đánh giá chất lượng cuộc sống: Bộ công cụ đo lường CLCS EQ-5D$5 \mathrm{~L}$ dành riêng cho người Việt Nam được chấm điểm dựa trên điểm số và hệ số (mức độ) chất lượng cuộc sống [4].

Nếu phân bố điểm chất lượng của NCT là phân bố chuẩn thì CLCS được mô tả theo giá trị trung bình.

Nếu phân bố điểm chất lượng của NCT là phân bố không chuẩn thì CLCS được mô tả theo giá trị trung vị.

2.3. Xử lý số liệu. Số liệu được quản lý, làm sạch và phân tích bằng phần mềm Stata 14. Thống kê mô tả được tính toán với giá trị trung bình, tỷ suất, tỷ lệ. Sử dụng mô hình hồi quy logistic để đánh giá yếu tố liên quan đến chất lượng cuộc sống, thông qua tỷ số chênh (OR) và khoảng tin cậy 95\% (CI 95\%) với mức ý nghĩa thống kê $p<0,05$.

2.4. Đạo đức trong nghiên cứu. Được sự đồng ý, hợp tác của địa phương. Người cao tuổi được cung cấp thông tin và tự nguyện đồng ý tham gia nghiên cứu. Các thông tin cá nhân thu được từ người cao tuổi chỉ sử dụng vào mục đích nghiên cứu khoa học và được giữ bí mật.

\section{KẾT QUẢ NGHIÊN CứU}

Bảng 1: Đặc điểm chung của quần thể nghiên cứu $(n=200)$

\begin{tabular}{|c|c|c|}
\hline Đặc điểm & \begin{tabular}{|c|} 
Tân số \\
(n)
\end{tabular} & $\begin{array}{l}\text { Tỷ lệ } \\
(\%)\end{array}$ \\
\hline $\begin{array}{l}\text { Tuối (tuối trung bình, khoảng } \\
\text { tuổi) }\end{array}$ & 200 & $\begin{array}{l}70,75 \\
\text { (tuôii) } \\
\end{array}$ \\
\hline $\begin{array}{ll}\text { Giới: } & \text { Nam } \\
& \text { Nữ }\end{array}$ & $\begin{array}{c}84 \\
116 \\
\end{array}$ & $\begin{array}{l}42,0 \\
58,0\end{array}$ \\
\hline $\begin{array}{c}\text { Tình trạng hôn nhân } \\
\text { Có vợ/ chồng } \\
\text { Góa }\end{array}$ & $\begin{array}{c}153 \\
47\end{array}$ & $\begin{array}{l}76,5 \\
23,5\end{array}$ \\
\hline $\begin{array}{c}\text { Điêu kiện kinh tế: Nghèo } \\
\text { Trung bình } \\
\text { Khá }\end{array}$ & $\begin{array}{l}29 \\
94 \\
77\end{array}$ & $\begin{array}{l}14,5 \\
47,0 \\
38,5\end{array}$ \\
\hline $\begin{array}{c}\text { Nghề nghiệp: Hưu trí } \\
\text { Đang lao động }\end{array}$ & $\begin{array}{c}31 \\
107 \\
\end{array}$ & $\begin{array}{l}15,5 \\
53,5\end{array}$ \\
\hline $\begin{array}{l}\text { Không làm việc/ không } \\
\text { có lương hưu }\end{array}$ & 62 & 31,0 \\
\hline Trình độ học vấnKhông đi học & 57 & 28,5 \\
\hline Từ trung học cơ sở trở xuống & 74 & 37,0 \\
\hline Trên trung học cơ sở & 69 & 34,5 \\
\hline $\begin{array}{l}\text { Hoàn cảnh sống: Sống cùng } \\
\text { gia đình có sự giúp đơ }\end{array}$ & 55 & 27,50 \\
\hline $\begin{array}{l}\text { Sống cùng gia đình không } \\
\text { có sự giúp đỡ }\end{array}$ & 16 & 8,0 \\
\hline Sống với vợ/chồng & 129 & 64,5 \\
\hline 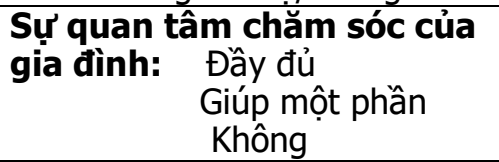 & $\begin{array}{l}120 \\
64 \\
16\end{array}$ & $\begin{array}{c}60,0 \\
32,0 \\
8,0\end{array}$ \\
\hline
\end{tabular}

Tham gia hoạt động Hội tại địa phương

\begin{tabular}{|c|c|c|}
\hline Không thang gia & 59 & 29,5 \\
\hline 1 hội & 70 & 35, \\
\hline Từ 2 hội trở lên & 71 & 35 \\
\hline Bị ốm trong một tháng qua & & \\
\hline Không ốm lần nào & & \\
\hline $\begin{array}{l}\text { Bị ốm môt lần } \\
\text { Bi ốm từ } 2 \text { lần trở lên }\end{array}$ & 61 & 30, \\
\hline $\begin{array}{l}\text { B! om tư } \angle \text { lan trơ len } \\
\text { Mắc bênh man tính }\end{array}$ & & \\
\hline Mắc 1 bênh mạn tính trở xuống & 109 & 5 \\
\hline Mắc từ 2 bệnh $\mathrm{m}$ & 91 & \\
\hline Khám sức k & & \\
\hline $\begin{array}{l}\text { Từ } 6 \text { tháng tr } \\
\text { Từ } 1 \text { năm }\end{array}$ & 76 & \\
\hline I U I na & 124 & \\
\hline Khá & 61 & \\
\hline Trung bì & & \\
\hline & 3 & \\
\hline
\end{tabular}

Người cao tuối có độ tuối trung bình là 75,75 và phần lớn có vợ/ chồng $(76,5 \%)$. Đa số người cao tuổi có điều kiên kinh tế trung bình $(47,0)$ và nhận được sự giúp đõ từ gia đình $(60 \%)$. Số người cao tuổi không bị ốm lần nào và mắc 1 bệnh mạn tính trở xuống lần lượt là $58,0 \%$ và $54,5 \%$. Bên cạnh đó, tỉ lệ người cao tuổi tự đánh giá sức khỏe tốt chiếm tỷ lệ 31,5\%. 
Bảng 2: Sự phân bố của người cao tuổi trên các mức độ của EQ-5D (n= 200)

\begin{tabular}{|c|c|c|c|c|c|c|}
\hline \multirow{2}{*}{ Các vấn đề } & \multicolumn{2}{|c|}{ Không vấn đề } & \multicolumn{2}{c|}{$\begin{array}{c}\text { Có ít vấn đề/ vấn } \\
\text { đề tương đối }\end{array}$} & \multicolumn{2}{c|}{ Có vấn đề nhiêu } \\
\cline { 2 - 7 } & $\mathbf{n}$ & $\mathbf{\%}$ & $\mathbf{n}$ & $\mathbf{\%}$ & $\mathbf{n}$ & $\mathbf{\%}$ \\
\hline Khả năng đi lại & 118 & 59,0 & 81 & 40,5 & 1 & 0,5 \\
\hline Tự chăm sóc bản thân & 126 & 63,0 & 73 & 36,5 & 1 & 0,5 \\
\hline Sinh hoạt thường lệ & 121 & 60,5 & 79 & 39,5 & - & - \\
\hline Đau/ khó chịu & 61 & 30,5 & 127 & 63,5 & 12 & 6,0 \\
\hline Lo lắng/ u sầu & 65 & 32,5 & 127 & 63,5 & 8 & 4,0 \\
\hline
\end{tabular}

Trong số 5 vấn đề của EQ-5D đau/ khó chịu được báo cáo gặp vấn đề nhiều nhất trong khi tự chăm sóc ít được báo cáo nhất. Nhìn chung $6,0 \%$ đối tượng trải qua đau/ khó chịu mức độ nhiều và $63,5 \%$ trải qua lo lắng/ u sầu với mức độ ít/ tương đối.

Bảng 3: Mối liên quan giữa đặc đîểm nhân khẩu học và chất lượng cuộc sống ( $n=200)$

\begin{tabular}{|c|c|c|c|c|c|}
\hline \multirow{2}{*}{ Đặc điểm } & \multicolumn{2}{|c|}{ CLCS tốt } & \multicolumn{2}{|c|}{ CLCS chưa tốt } & \multirow{2}{*}{ OR $(95 \% \mathrm{CI})$} \\
\hline & $\mathbf{n}$ & $\%$ & $\mathbf{n}$ & $\%$ & \\
\hline Nhóm tuối: $60-69$ & 87 & 84,47 & 16 & 15,53 & 1 \\
\hline 70 tuối trở lên & 6 & 6,19 & 91 & 93,81 & $82,5(30,8-220,4)$ \\
\hline Giới tính: & 50 & 59,52 & 34 & 40,48 & 1 \\
\hline Nữ & 53 & 45,96 & 63 & 54,31 & $1,75(0,98-3,1)$ \\
\hline Trình độ học vấn: Trên THCS & 45 & 65,2 & 24 & 34,8 & 1 \\
\hline Từ THCS trở xuống & 38 & 51,3 & 36 & 48,7 & $1,78(0,91-3,5)$ \\
\hline Không đi hoc & 20 & 35,1 & 37 & 64,9 & $3,46(1,6-7,2)$ \\
\hline Tình trạng hôn nhân: Có vợ/ chồng & 100 & 65,5 & 53 & 34,6 & 1 \\
\hline Góa & 3 & 6,4 & 44 & 93,6 & $27,8(6,8-113,1)$ \\
\hline Nghề nghiệp: Đang lao động & 78 & 72,90 & 29 & 27,10 & 1 \\
\hline Hưu trí & 15 & 48,39 & 16 & 51,61 & $2,87(1,3-6,5)$ \\
\hline Không làm viêc/ không có lươr & 10 & 16,13 & 52 & 83,87 & $13,9(6,3-31,1)$ \\
\hline Điều kiện kinh tế: Khá & 53 & 69,83 & 24 & 31,17 & 1 \\
\hline Trung bình & 40 & 42,55 & 54 & 57,45 & $2,98(1,6-5,6)$ \\
\hline Nghèo & 10 & 34,48 & 19 & 65,52 & $4,19(1,7-10,4)$ \\
\hline Hoàn cảnh sống: Sống cùng vớ/ chồng & 86 & 66,67 & 43 & 33,33 & 1 \\
\hline Sống cùng người thân có sự giúp đõ & 16 & 29,09 & 39 & 70,91 & $4,88(2,5-9,7)$ \\
\hline $\begin{array}{l}\text { Sống cùng người thần } \\
\text { không có sự giúp đỡ }\end{array}$ & 1 & 6,24 & 15 & 93,75 & $30(3,8-234,7)$ \\
\hline Sự giúp đỡ từ gia đình: Đâyy đủ & 85 & 70,83 & 35 & 29,17 & 1 \\
\hline Môt phần & 17 & 26,56 & 47 & 73,44 & $6,71(3,4-13,3)$ \\
\hline Không & 1 & 6,25 & 15 & 93,75 & $36,4(4,6-286,4)$ \\
\hline \multicolumn{6}{|l|}{ Tham gia hội tại địa phương } \\
\hline Từ hai hội trở lên & 52 & 73,24 & 19 & 26,76 & 1 \\
\hline Một hội & 37 & 62,71 & 22 & 37,29 & $1,63(0,77-3,4)$ \\
\hline Không tham gia & 14 & 20,0 & 56 & 80,0 & $10,9(4,98-24,04)$ \\
\hline
\end{tabular}

OR: Tỷ số chênh; CI 95\%: Khoảng tin cậy 95\%

Nhóm 60-69 tuối có chất lượng cuộc sống tốt cao hơn nhóm từ 70 tuổi trở lên (OR: 82,5; $95 \%$ CI: 30,8 - 220,4). Chất lượng cuộc sống tốt ở người cao tuổi có trình độ học vấn trên trung học cơ sở(THCS) cao hơn so với nhóm không đi học (OR: 3,46; 95\%CI: 1,6-7,2). Người cao tuổi có vợ/ chồng có chất lượng sống tốt hơn nhóm góa (OR: 27,8; 95\%CI: 6,8 - 113,1). Ngươi cao tuổi đang lao động có chất lượng cuộc sống tốt hơn nhóm không làm việc/ không có lương hưu (OR: 13,9; 95\%CI: 6,3-31,1). Nhóm có điều kiện kinh tế khá có chất lượng cuộc sống tốt cao hơn so với nhóm nghèo (OR: 4,19; 95\%CI: $1,7-10,4)$. Người cao tưởi sống chung với vợ/ chồng có chất lượng cuộc sống tốt hơn so với nhóm sống cùng người thân không có sự giúp đõ (OR: $30 ; 95 \%$ CI: 3,8 - 234,7). Người cao tuổi nhận được sự giúp đõ từ gia đình có chất lượng cuộc sống tốt cao hơn hẳn so với nhóm không nhân được sự giúp đõ từ gia đình (OR: 30; 95\%CI: 3,8 - 234,7). Chất lượng cuộc sống tốt ở nhóm tham gia từ hai hội trở lên ở địa phương cao hơn so vơi nhóm không tham gia (OR: 10,9; 95\%CI: 4,98-24,04). 
Bảng 4: Môi liên quan giữa tình trạng sức khỏe và chât lượng cuộc sống (n=200).

\begin{tabular}{|c|c|c|c|c|c|}
\hline \multirow{2}{*}{ Đặc điểm } & \multicolumn{2}{|c|}{ CLCS tốt } & \multicolumn{2}{|c|}{ CLCS chưa tốt } & \multirow{2}{*}{ OR $(95 \% \mathrm{CI})$} \\
\hline & $\mathbf{n}$ & $\%$ & $\mathbf{n}$ & $\%$ & \\
\hline \multicolumn{6}{|l|}{ Số bệnh mạn tính mắc phải } \\
\hline Mắc một bệnh trở xuống & 72 & 66,0 & 37 & 34,07 & 1 \\
\hline Mắc từ hai bệnh trở lên & 31 & 34,07 & 60 & 65,93 & $3,77(2,1-6,8)$ \\
\hline \multicolumn{6}{|l|}{ Bị ốm tháng qua } \\
\hline Không ốm lần nào & 71 & 61,21 & 45 & 38,79 & 1 \\
\hline Bị ốm một lân & 27 & 44,26 & 34 & 55,74 & $1,99(1,1-3,7)$ \\
\hline Bị ốm từ hai lần trở lên & 5 & 21,74 & 18 & 78,26 & $5,68(1,97-16,4)$ \\
\hline \multicolumn{6}{|l|}{ Khám sức khỏe định kỳ } \\
\hline Từ 6 tháng trở xuống/ lần & 47 & 61,84 & 39 & 38,16 & 1 \\
\hline Từ 1 năm trở lên/ lần & 56 & 45,16 & 68 & 54,84 & $1,97(1,1-3,5)$ \\
\hline \multicolumn{6}{|l|}{ Tự đánh giá sức khỏe } \\
\hline Tốt & 62 & 98,41 & 1 & 1,95 & 1 \\
\hline Khá & 41 & 67,21 & 20 & 32,79 & $30,24(3,9-234,2)$ \\
\hline Trung bình & 0 & 0,00 & 44 & 100 & - \\
\hline Yễu & 0 & 0,00 & 32 & 100 & - \\
\hline
\end{tabular}

OR: Tỷ số chênh; CI 95\%: Khoảng tin cậy 95\%

Người cao tuổi mắc một bệnh mạn tính trở xuống có chất lượng cuộc sống tốt cao hơn so với nhóm mắc từ hai bệnh trở lên (OR: 3,77 ; $95 \%$ CI: $2,1-6,8)$. Chất lượng cuộc sống tốt ở nhóm không ốm lần nào cao hơn so với nhóm bị ốm một lân (OR: 1,99; 95\%CI: $1,1-3,7$ ) và nhóm bị ốm từ hai lần trở lên (OR: 5,$68 ; 95 \% \mathrm{CI}$ : 1,97 - 16,4). Người cao tuổi khám sức khỏe định kỳ từ 6 tháng trở xuống/ lần có chất lượng cuộc sống tốt cao hơn so với nhóm khám sức khỏe định kỳ từ 1 năm trở lên/ lần (OR: 1,97 95\%CI: $1,1-3,5)$ và nhóm tự đánh giá sức khỏe tốt có chấ lượng cuộc sống tốt cao hơn so với nhóm tự đánh giá sức khỏe khá (OR: 30,24; 95\%CI: 3,9234,2).

\section{BÀN LUÂ̂N}

Nghiên cứu này nằm trong số ít các nghiên cứu tại Việt Nam sử dụng bộ giá trị EQ-5D-5L dành riêng cho người Việt Nam. Chỉ số EQ-ED trung bình của những người lớn tuổi trong nghiên cứu này là 0,77 và điều này thay đổi đáng kể theo các yếu tố nhân khẩu học, kinh tế xã hội và tình trạng sức khỏe cá nhân. Trong nghiên cứu này, kết quả phấn bố của người cao tuổi trên 5 vấn đề $E Q-5 D$ tương tự như được báo cáo cho người cao tuổi của nghiên cứu tại Chí Linh, Việt Nam năm 2017 [5], đau khó chịu là vấn đề được báo cáo nhiều nhất.

Kiểm tra mối liên quan giữa các yếu tố và chất lượng cuộc sống không cho thây sự khác biệt giữa người cao tuổi nam và nữ. Kết quả ngày cũng được chỉ ra ở nghiên cứu người cao tuổi nông thôn ở Ai Cập và Trung Quốc [6],[7].
Nhưng kết quả này cũng trái ngược với một số nghiên cứu khi cho biết chất lượng cuộc sống ở nữ giới được báo cáo thấp hơn nam giới [3],[8]. Điều này có thể lý giải do mặc dù phụ nữ có nhiều khả năng bị các tình trạng suy nhược nhưng kém nghiêm trọng và không gây tử vong, ảnh hưởng tới chất lượng cuộc sống như nam giới. Do đó mối quan hệ này cần được nghiên cứu thêm. Chất lượng cuộc sống của người cao tuổi tại xã Thạch Thán có mối tương quan với tuổi ( $\geq 70)$, không lao động, không tham gia hội tại địa phương và không nhận được sự giúp đõ̃ từ gia đình. Tương tự như các nghiên cứu trước đây [5], phát hiện của chúng tôi cho thấy có mối tương quan nghịch giữa các yếu tố này tới chất lượng cuộc sống. Điều này có thể được lý giải bởi tuổi cao, cô đơn, không có việc làm là yếu tố tác động đến nhiều khía cạnh của CLCS như làm suy giảm một số chức năng cơ thể, dẫn đến sức khỏe yếu dẩn đi... hoăc ảnh hưởng đến tâm lý, tình cảm, giao tiếp của NCT. Những người cao tuổi có trình độ trên trung học cơ sở có chất lượng cuộc sống tốt cao hơn so với những người có trình độ học vấn từ trung học cơ sở trở xuống và không đi học. Phát hiện này có thể giải thích bởi mối tương quan tích cực giữa giáo dục được cho là có tác động tích cực đến tình trạng sức khỏe vì những người có trình độ học vấn cao hơn được cho là được cung cấp thổng tin tốt hơn về các vấn đề sức khỏe, chế độ ăn uống và các biện pháp phòng chống bệnh tật dẫn đến tình trạng sức khỏe tốt hơn, do đó dẫn đến chất lượng cuộc sống cao hơn. Nghiên cứu còn cho thấy mối tương quan giữa chất lượng cuộc sống với đời 
sống của người cao tuổi. Những người cao tuổi có vợ/ chồng, đang sống chung với vợ chồng và nhận được sự giúp đõ đây đủ từ gia đình có chất lượng cuộc sống tốt cao hơn hẳn so với những người cao tuổi góa, sống với người thân không có sự giúp đõ và không nhận được sự giúp đõ nào từ gia đình. Điều này có thể cho thấy rằng sự trao đổi tình cảm trong một cặp vợ chồng có vai trò quan trọng trong việc duy trì các chức năng thể chất ở tuổi già, các cặp vợ chồng dễ giúp đõ và chia sẻ với nhau hơn về những vấn đề trong cuộc sống. Nghiên cứu tại Tamilnadu (2012) [9] đã̃ góp phần lý giải nguyên nhân dẫn đến thực trạng trên do những NCT góa chồng/vợ có sức khỏe thấp hơn so với những người đang sống với vợ/chồng. Nghiên cứu của Hoàng Văn Minh chỉ ra thêm rằng những người sống với vợ/chồng hoặc với các thành viên khác trong gia đình có điểm CLCS cao hơn những người sống neo đơn. Nghiên cứu cũng khám phá ra rằng nếu gia đình bao gồm nhiều NCT thì khả năng có điểm CLCS thấp ít hơn. Sức khỏe tốt được công nhận là yếu tố quyết định chất lượng cuộc sống tốt ở người cao tuổi [6]. Tình trạng bệnh mạn tính mà đi kèm với lão hóa có ảnh hưởng bất lợi đến chất lượng cuộc sống của người cao tuổi. Trong nghiên cứu này, những người cao tuổi càng có nhiều hơn một bệnh mãn tính càng làm giảm chất lượng cuộc sống. Do đó, những người cao tuổi mắc bệnh mãn tính nên được chăm sóc hỗ trợ nhiều hơn. Điều này phù hợp với phát hiện của một nghiên cứu trước đây ở những người cao tuổi vùng nông thôn Việt Nam. Bên cạnh đó nghiên cứu cũng cho thấy số lần ốm trong một tháng trước nghiên cứu có mối tương quan với chất lượng cuộc sống. Số lần ốm càng nhiều tỷ lệ chất lượng cuộc sống chưa tốt ở người cao tuổi càng cao. Kết quả thống nhất với nhóm nghiên cứu Trường Đại học YTCC khi tìm ra CLCS có liên quan đển tình trạng ốm trong tháng và mắc bệnh mạn tính. Kết quả nghiên cứu cũng cho thấy nhóm tự đánh giá sức khỏe tốt có điểm CLCS tốt cao hẳn so với nhóm khá. Điều này có thể được lý giải bởi đối với NCT tình trạng lão hóa đi kèm với những vấn đề sức khỏe khá phổ biến. Khả năng chấp nhận tình trạng sức khỏe dẫn đến những cảm nhận về ành hưởng từ các vấn đề sức khỏe có sự khác nhau. Vì vậy, CLCS của NCT ảnh hưởng bởi sự đánh giá chủ quan về sức khỏe của chính họ. Nhìn chung, các vấn đề của người cao tuổi ngày càng gia tăng theo độ tuổi của họ, vì vậy cần sự hợp tác toàn diện của gia đình và các cơ quan chức năng có trách nhiệm. Với vai trò quan trọng của hỗ trợ xã hội trong việc thúc đẩy chất lượng cuộc sống của người cao tuổi trong các lĩnh vực khác nhau, nó có thể được coi là một yếu tố quan trọng trong việc cung cấp chất lượng cuộc sống tốt cho các cá nhân.

\section{KẾT LUÂN}

Chất lượng cuộc sống của NCT xã Thạch Thán chưa thực sự cao ở mức điểm 0,77 (SD = $\pm 0,13)$. Với $51,5 \%$ NCT có điểm chất lượng cuộc sống đạt tốt. Các yếu tố liên quan, có ảnh hưởng tích cực tới chất lượng cuộc sống của người cao tuổi là: Yếu tố cá nhân: Nhóm 60 - 69, nhóm đang lao động, điều kiện kinh tế khá, có vợ/ chồng. Yếu tố cuộc sống xã hội: Sống chung với vợ chồng, nhận được sự giúp đỡ đầy đủ từ gia đình, tham gia từ 2 hội trở lên tại đại phương. Yễu tố sức khỏe: Mắc 1 bệnh mạn tính trở xuống, không bị ốm lần nào trong tháng qua, khám sức khỏe từ 6 tháng trở xuống/ lần, tự đánh giá sức khỏe tốt.

\section{TÀI LIỆ THAM KHẢO}

1. Teerawichitchainan BLG. Socioeconomic status and health among older adults in Vietnam. IUSSP International Population Conference. August, 2013 2001 - 2011:26-31.

2. Qũy Dân Số Liên Hợp Quốc. Già hóa dân số và người cao tuổi ở Việt Nam. Thức trang, dự báo và một số khuyến nghị chính sách. 2011:12 - 55. UNFPA VIETNAM. 7/2011.

3. Hoang Van Minh, et al. Patterns of health status and quality of life among older people in rural Viet Nam. Global Health Action. December 1, 2010 2010;3(1):2124.

4. Mai Quynh Vu, et al. An EQ-5D-5L Value Set for Vietnam. Quality of Life Research. 2020-07-01 2020;29(7):1932-1933.

5. Thanh Huong Nguyen, et al. Determinants of Health-Related Quality of Life Among Elderly: Evidence From Chi Linh Town, Vietnam. 2017 (1):1-11.

6. Hamed AF ST, Hassan ATA. Study of health related quality of life (HRQoL) among rural elderly in upper Egypt (Edfa Village-Sohag). Egypt J Community Med. April 4, 2017 2012;30(2)

7. Liu N ZL, Li Z, Wang J. Health-related quality of life and long-term care needs among elderly individuals living alone: a cross-sectional study in rural areas of Shaanxi Province, China. BMC Public Health and Quality of Life Outcomes. 2013;13:313.

8. Sarani M KT, Mohseni M, et al. The correlation between chronic diseases and quality of life among the elderly. Int J Pharm Technol. 2016;8:1228112296.

9. Nagarani KSv. A Study on Quality of Life of Elderly Population in Mettupalayam, a Rural Area of Tamilnadu. National Journal of Research in Community Medicine. 2012:139 -143. 